\title{
A comparative study to find out the relationship between the inner inter-canthal distance, interpupillary distance, inter-commissural width, inter-alar width, and the width of maxillary anterior teeth in Aryans and Mongoloids
}

This article was published in the following Dove Press journal:

Clinical, Cosmetic and Investigational Dentistry

22 February 2016

Number of times this article has been viewed

\author{
Meena Kumari Mishra \\ Raj Kumar Singh \\ Pramita Suwal \\ Prakash Kumar Parajuli \\ Pragya Shrestha \\ Dharanidhar Baral \\ Department of Prosthodontics, \\ BP Koirala Institute of Health \\ Sciences, Dharan, Nepal
}

Correspondence: Meena Kumari Mishra Department of Prosthodontics, BP Koirala Institute of Health Sciences, PO Box 7053, Dharan, Nepal Tel +9779842043884

Email drmeenamishra400@gmail.com
Background: One of the most confusing and difficult aspects of complete denture prosthodontics is the selection of appropriately sized maxillary anterior denture teeth. Various guidelines have been suggested for determining the size of anterior teeth, but different opinions have been reported regarding their significance. In the study reported here, the relationships between facial measurements and the width of maxillary anterior teeth in two ethnic groups, namely Aryans and Mongoloids, were determined.

Objective: The aims of the study were to determine the inner inter-canthal distance (ICAD), inter-pupillary distance (IPD), inter-commissural width (ICOW), inter-alar width (IAW), and the combined width of maxillary anterior teeth $(\mathrm{CW})$ in Aryans and Mongoloids and to determine the relationships between these measurements.

Materials and methods: Impressions of the teeth of 170 dentulous subjects ( 85 males and 85 females) were made with alginate then Type IV gypsum product was poured in. Measurements of the cast maxillary anterior teeth at their widest dimension (contact areas) were made with the Boley gauge. ICAD, IPD, ICOW, and IAW distances were also measured with a Boley gauge.

Results: For all 170 subjects, 85 Aryans and 85 Mongoloids, Pearson's correlation coefficient $(r)$ for IAW, IPD, ICOW, ICAD, and CW was calculated. In Aryans, highly significant $(P<0.001)$ but weak correlations were found between CW and IAW, IPD, and ICOW. In Mongoloids, a highly significant $(P<0.001)$ and weak correlation was found only between $\mathrm{CW}$ and IPD.

Conclusion: Within the limitations of this study, the results suggest that the IAW, IPD, and ICOW for Aryans and IPD for Mongoloids can be used as a preliminary method for determining the width of the maxillary anterior teeth in edentulous patients.

Keywords: maxillary anterior denture teeth, facial measurements, maxillary anterior teeth width, Nepal

\section{Introduction}

In Nepal, the population aged 65 years or above increased from $6.2 \%$ in 1971 to $8.4 \%$ in 2001. ${ }^{1}$ This implies that the demand for restoration of edentulous patients will remain high for the foreseeable future. One of the most confusing and difficult aspects of complete denture prosthodontics is the selection of appropriately sized maxillary anterior denture teeth. ${ }^{2}$ Various guidelines have been suggested for determining the size of the teeth, but different opinions have been reported regarding their significance. ${ }^{3,4}$ 
The width of the teeth is considered by some authors to be more critical than the length., ${ }^{2,5,7-10}$ Shillingberg ${ }^{6}$ reported that the combined width of maxillary central incisors occupied $37 \%$ of the circumferential arch distance between the distal surface of the canines. The combined width of the lateral incisors and canines accounted for $31 \%$ and $32 \%$ of the distance, respectively. ${ }^{6}$

According to McArthur, ${ }^{10}$ patients' own natural teeth are the best guides, and records of these should be obtained whenever possible. Whenever there are pre-extraction records such as casts, radiographs, facial photographs, and previous dentures, it becomes easy for the practitioner to select the teeth, ${ }^{11}$ but when there are no pre-extraction records, the size of the denture tooth has to be determined by various guides. Over the past several decades, various methods and/ or guides have been topics of controversy. ${ }^{12}$ However, most of the studies regarding the selection of complete denture teeth were conducted in Caucasian population samples, ${ }^{13}$ and findings have been extrapolated to other ethnic groups. So in the study reported here, we wanted to determine the relationship between facial measurements and the width of anterior teeth in two ethnic groups, namely Aryans and Mongoloids. The findings may be helpful in establishing the relationship between these facial measurements and maxillary anterior teeth, and compared with the findings for other races and ethnic groups.

\section{Materials and methods}

This hospital-based prospective observational study was conducted in 170 dentate subjects in the Department of Prosthodontics, College of Dental Surgery, BP Koirala Institute of Health Sciences, Dharan, Nepal. Out of the 170 subjects, $85(50 \%)$ were Aryans and 85 (50\%) were Mongoloids. The age of the patients in this study ranged from 19 to 48 years. The mean age \pm standard deviation was $23.60 \pm 5.39$ years. Most of the patients - that is, 112 patients $(65.9 \%)$ - were in the age group 21-30 years followed by 46 patients in the age group of $\leq 20$ years.

Inclusion criteria were $>18$ years old; either Aryan or Mongoloid; born in Nepal; with an Angle Class I molar relationship, pleasing profile, and intact morphologically normal permanent dentition up to the second molar. Subjects with a history of orthodontic treatment; a Class II or Class III molar relationship; gingival inflammation and hypertrophy in the upper anterior region; severe attrition; crowns or proximal restorations placed in the anterior teeth; and a history of congenital anomaly, orbital disease, trauma, or facial surgery were excluded.

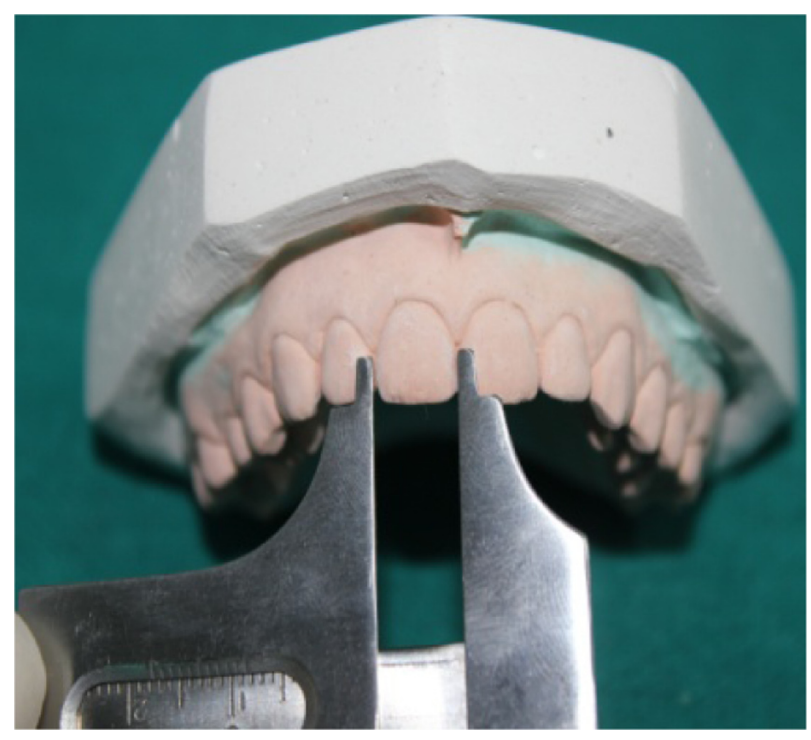

Figure I Measurement of mesiodistal width of central incisor.

Approval for the study was obtained from Institutional Ethis Review Board BPKIHS, Dharan, on December 4, 2013. The subjects provided written informed consent. The study was conducted from December 2013 to July 2014.

The subjects were comfortably seated on a dental chair in a relaxed state in an upright position with the head resting firmly against the headrest. Maxillary impressions of selected subjects were made with an irreversible hydrocolloid impression material tray (Zelgan ${ }^{\circledR} 2002$ Dustfree Alginate Impression Material, DENTSPLY DeTrey GmbH, Konstanz, Germany)

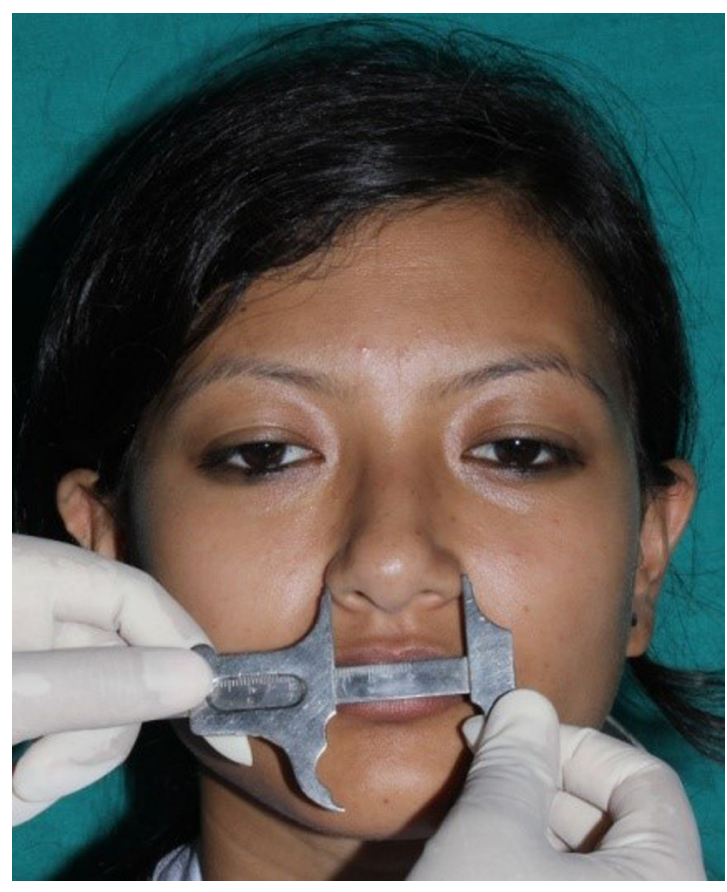

Figure 2 Measurement of inter-alar width. 

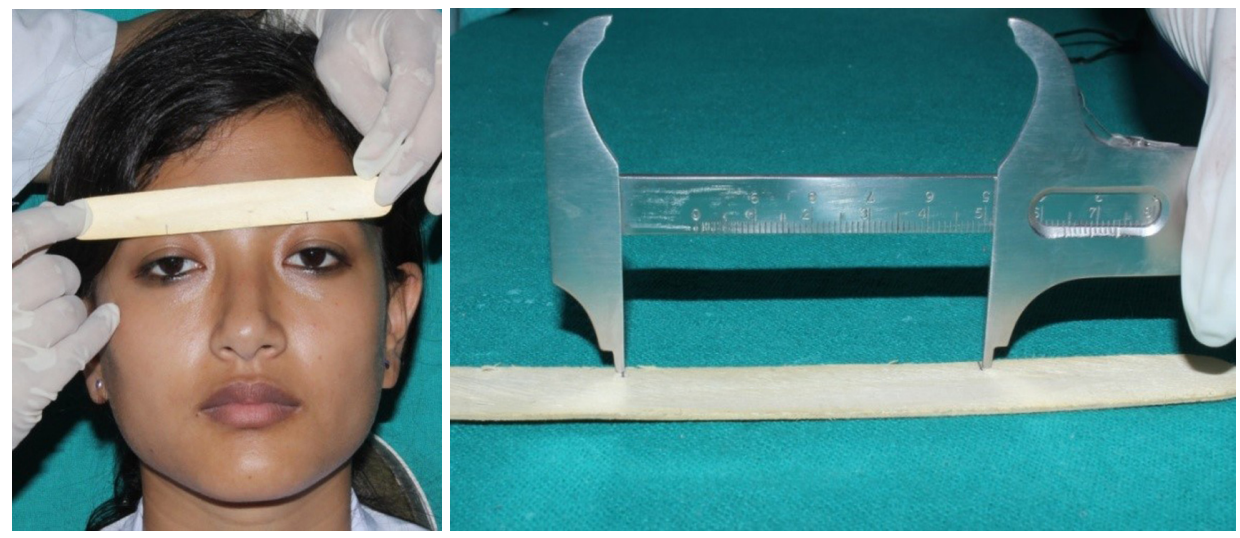

Figure 3 Measurement of interpupillary distance.

and poured into a Type IV die stone (Kalrock, Kalabhai Karson Pvtd Ltd, Mumbai, India). The mesiodistal width of the maxillary anterior teeth was measured from the casts with a Boley gauge (Taurus 811-2, SS Medident Instruments [Pvt] Ltd, Sialkot, Pakistan) as shown in Figure 1.

\section{Determination of the combined width of} the maxillary anterior teeth $(\mathrm{CW})$, interalar width (IAW), interpupillary distance (IPD), inter-commissural width (ICOW), and inner inter-canthal distance (ICAD)

The IAW was measured as the distance between the widest points on the outer surface of the alae of the nose on either

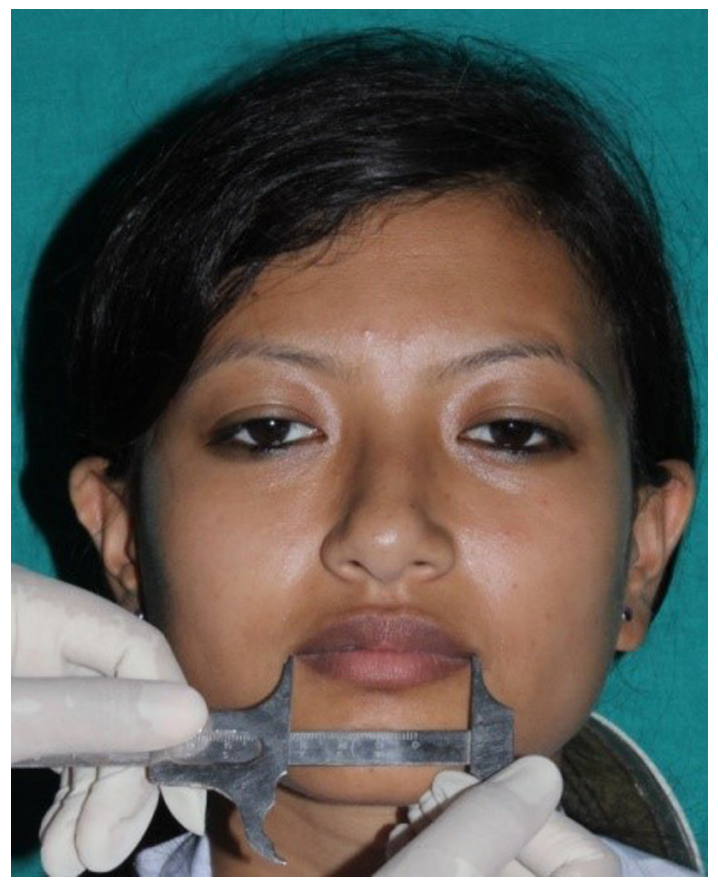

Figure 4 Measurement of inter-commissural width. side (Figure 2). For the measurement of IPD, the midpoint of the pupils was marked on a wooden tongue spatula (Figure 3). The ICOW was determined by measuring the maxillary lip vermilion from commissure to commissure (Figure 4). The ICAD was measured as a distance between the medial angle of the palpebral fissure of the eyes (Figure 5). Distances were measured using a Boley gauge without the application of pressure.

\section{Statistical methods}

Collected data were entered into Microsoft ${ }^{\circledR}$ Excel 2007 software and converted into SPSS (version 11.5) for statistical analysis. Descriptive statistics were calculated (mean and standard deviation) and also tabular presentation was done. For inferential statistics, Pearson's correlation coefficient was

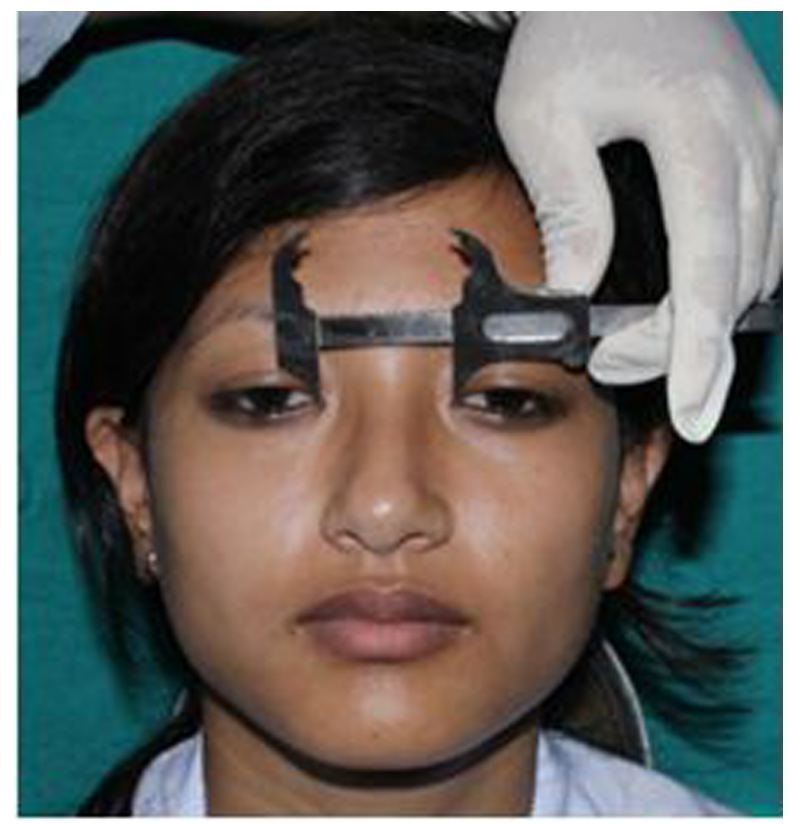

Figure 5 Measurement of inner inter-canthal distance. 
applied to find out significant correlations between the groups at a $95 \%$ confidence interval, where $P=0.05$.

\section{Results}

The mean values of CW, IAW, IPD, ICOW, and ICAD in Aryans and Mongoloids are presented in Table 1.

Pearson's correlation coefficients between CW, IAW, IPD, ICOW, and ICAD for the total population, Aryans, and Mongoloids are presented in Tables 2, 3, and 4, respectively. A highly significant but weak correlation between $\mathrm{CW}$ and IAW at the 0.001 level (two-tailed) was found in the total population and Aryans, and a significant correlation at the 0.05 level (two-tailed) was found in Mongoloids. A highly significant correlation between CW and IPD was found in the total population, Aryans, and Mongoloids at the 0.001 level. Pearson's correlation coefficient of CW and ICOW was found to be highly significant and negative in Aryans, while no correlation was found in the total population or Mongoloids. Significant correlation between CW and ICAD at the 0.05 level (two-tailed) was found in the Mongoloids and no correlation was found in the total population and Aryans.

\section{Discussion}

Scandrett et al ${ }^{14}$ evaluated bizygomatic distance, inter-alar width, inter-commissural width, sagittal cranial diameter, inter-buccal frenulum distance, philtrum width, and age as predictors of the width of the maxillary anterior teeth and central incisors. The investigators concluded that no single predictor was accurate enough for clinical application. Therefore, it appears that more than one variable is needed to predict the width of the maxillary anterior teeth. So this study was conducted to determine the relationship of facial measurements, ie, ICAD, IPD, ICOW, and IAW of the maxillary anterior teeth.

In the study presented here, Pearson's correlation coefficient for CW and IAW was found to be weak, negative (except in Aryans), and highly significant at the 0.001 level in the total population and Aryans. A significant correlation at the 0.05 level (two-tailed) was found in Mongoloids. Ellakwa et al ${ }^{15}$ found a weak relationship between IAW and CW, similar to our study, in which Pearson's correlation coefficient was 0.38 for the total population. Patel et al, ${ }^{15}$ Wazzan et al, ${ }^{16}$ Scandrett et al, ${ }^{17}$ and Sinavarat et $\mathrm{al}^{18}$ found no significant correlation between IAW and CW. Pearson's correlation coefficient for CW and IPD was found to be 0.439 at the 0.001 level (two-tailed) in our study. A highly significant correlation was found in the total population, Aryans, Mongoloids at the 0.001 level (two-tailed), which is contradictory to the finding of Wazzan et $\mathrm{al}^{16}$ and Ellakwa et al, ${ }^{14}$ who found no significant correlation.

We also found that Pearson's correlation coefficient for CW and ICOW was highly significant in Aryans at the 0.001 level (two-tailed). No significant correlation was found in the total population. Wazzan et al, ${ }^{16}$ Hussain et al, ${ }^{19}$ Scandrett et al, ${ }^{17}$ Ellakwa et al, ${ }^{14}$ and Sinavarat et al ${ }^{18}$ similarly found no significant correlation between ICOW and CW.

Table I Group statistics of CW, IAW, IPD, ICOW, and ICAD, comparing ethnicities

\begin{tabular}{|c|c|c|c|c|c|}
\hline Ethnicity & $\mathbf{N}$ & Mean \pm SD & Minimum-maximum & $P$-value & Remark \\
\hline \multicolumn{6}{|l|}{$\mathrm{CW}$} \\
\hline Aryan & 85 & $46.95 \pm 3.37$ & $41.00-53.50$ & 0.010 & Significant \\
\hline Mongoloids & 85 & $45.54 \pm 3.62$ & $37.50-56.00$ & & \\
\hline \multicolumn{6}{|l|}{ IAW } \\
\hline Aryan & 85 & $40.56 \pm 5.16$ & $32.50-60.50$ & $<0.001$ & Significant \\
\hline Mongoloids & 85 & $37.4 I \pm 4.83$ & $21.00-48.00$ & & \\
\hline \multicolumn{6}{|l|}{ IPD } \\
\hline Aryan & 85 & $61.92 \pm 5.85$ & $46.00-75.00$ & $<0.001$ & Significant \\
\hline Mongoloids & 85 & $57.50 \pm 7.23$ & $39.00-72.00$ & & \\
\hline \multicolumn{6}{|l|}{ ICOW } \\
\hline Aryan & 85 & $50.76 \pm 6.34$ & $30.00-61.10$ & $<0.001$ & Significant \\
\hline Mongoloids & 85 & $45.82 \pm 7.96$ & $30.00-63.00$ & & \\
\hline \multicolumn{6}{|l|}{ ICAD } \\
\hline Aryan & 85 & $34.12 \pm 5.10$ & $24.00-56.00$ & 0.370 & Not significant \\
\hline Mongoloids & 85 & $33.49 \pm 3.95$ & $22.00-43.00$ & & \\
\hline
\end{tabular}

Note: $P$-value significant at $\leq 0.05$ level.

Abbreviations: CW, combined width of maxillary anterior teeth; IAW, inter-alar width; ICAD, inter-canthal distance; ICOW, inter-commissural width; IPD, interpupillary distance; SD, standard deviation. 
Table 2 Correlation matrix for combined width of maxillary anterior teeth $(\mathrm{CW})$ with inter-alar width (IAW), interpupillary distance (IPD), inter-commissural width (ICOW), and inter-canthal distance (ICAD) in total population

\begin{tabular}{llllll}
\hline Variable & \multicolumn{6}{l}{ Pearson's correlation coefficient value (P-value) } \\
\cline { 2 - 6 } & CW & IAW & IPD & ICOW & ICAD \\
\hline CW & I & - & - & - & - \\
IAW & -0.201 & I & - & - & - \\
& $(0.009)$ & & & & \\
IPD & 0.439 & -0.033 & I & - & - \\
& $(<0.001)$ & $(0.669)$ & & & \\
ICOW & 0.004 & 0.294 & 0.252 & I & - \\
& $(0.958)$ & $(0.000)$ & $(0.001)$ & & \\
ICAD & 0.146 & 0.170 & 0.018 & -0.047 & I \\
& $(0.057)$ & $(0.027)$ & $(0.819)$ & $(0.544)$ & \\
\hline
\end{tabular}

Note: $P$-value significant at $\leq 0.05$ level.

Pearson's correlation coefficient for CW and ICAD was significant at the 0.05 level (two-tailed) in Mongoloids in our study, but no significant correlation was found in the total population or Aryans. Gomes et $\mathrm{a}^{20}$ found a significant correlation of ICAD and $\mathrm{CW}$ to the combined mesiodistal width of six teeth using Spearman's rank correlation coefficient. They found Spearman's rank correlation coefficient for ICAD and IAW to be 0.232 and 0.205 , respectively. Lucas et $\mathrm{al}^{21}$ found correlation between ICAD and $\mathrm{CW}$ where the value of Pearson's correlation coefficient was $0.302(P$-value $0.006)$.

\section{Limitations}

This study has several limitations. First, only two ethnic groups were included so the findings cannot be extrapolated to other ethnic groups. Second, the accuracy in determining the dimensions of teeth was compromised in two stages - one

Table 3 Correlation matrix for combined width of maxillary anterior teeth $(\mathrm{CW})$ with inter-alar width (IAW), interpupillary distance (IPD), inter-commissural width (ICOW), and inter-canthal distance (ICAD) in Aryans

\begin{tabular}{llllll}
\hline Variable & \multicolumn{5}{l}{ Pearson's correlation coefficient value (P-value) } \\
\cline { 2 - 6 } & CW & IAW & IPD & ICOW & ICAD \\
\hline CW & I & - & - & - & - \\
IAW & -0.342 & I & - & - & - \\
& $(<0.00 I)$ & & & & \\
IPD & -0.380 & -0.119 & I & - & - \\
& $(<0.00 I)$ & $(0.276)$ & & & \\
ICOW & -0.337 & $0.4 I I$ & -0.356 & I & - \\
& $(0.002)$ & $(<0.00 I)$ & $(<0.00 I)$ & & \\
ICAD & $0.07 I$ & 0.087 & -0.116 & -0.104 & I \\
& $(0.518)$ & $(0.43 I)$ & $(0.291)$ & $(0.342)$ & \\
\hline
\end{tabular}

Note: $P$-value significant at $\leq 0.05$ level.
Table 4 Correlation matrix for combined width of maxillary anterior teeth (CW) with inter-alar width (IAW), interpupillary distance (IPD), inter-commissural width (ICOW), and inter-canthal distance (ICAD) in Mongoloids

\begin{tabular}{llllll}
\hline Variable & \multicolumn{5}{l}{ Pearson's correlation coefficient value (P-value) } \\
\cline { 2 - 6 } & CW & IAW & IPD & ICOW & ICAD \\
\hline CW & I & - & - & - & - \\
IAW & -0.217 & $\mathrm{I}$ & - & - & - \\
& $(0.046)$ & & & & \\
IPD & 0.425 & -0.167 & $\mathrm{I}$ & - & - \\
& $(<0.00 \mathrm{I})$ & $(0.127)$ & & & \\
ICOW & 0.136 & 0.056 & 0.501 & $\mathrm{I}$ & - \\
& $(0.213)$ & $(0.612)$ & $(<0.001)$ & & \\
ICAD & 0.218 & 0.256 & $0.11 \mathrm{I}$ & -0.046 & $\mathrm{I}$ \\
& $(0.045)$ & $(0.612)$ & $(0.312)$ & $(0.673)$ & \\
\hline
\end{tabular}

Note: $P$-value significant at $\leq 0.05$ level.

during impression making and the other during cast making. This could have been avoided if the teeth were measured intra-orally but the patients' comfort would have been compromised. Facial measurements were done on softtissue landmarks and intra-operator variation in reading was observed with the same patients because of inconsistent pressure during measuring. A photographic method with calibration could have been used to avoid this problem.

\section{Conclusion}

For all 170 subjects, Pearson's correlation coefficient for IAW, IPD, ICOW, ICAD, and CW were calculated for the total population, Aryans, and Mongoloids. Pearson's correlation coefficient for CW and IAW was found to be a highly significant but weak correlation at the 0.001 level (two-tailed) in the total population and Aryans. Pearson's correlation coefficient for $\mathrm{CW}$ and ICOW was found to be highly significant in Aryans at the 0.001 level (two-tailed). A highly significant correlation was found between IPD and CW in the total population, Aryans, and Mongoloids at the 0.001 level (two-tailed). For Aryans, IAW, IPD, and ICOW can be used to determine anterior teeth widths. For Mongoloids, IPD can be used to determine anterior teeth widths.

\section{Acknowledgments}

The authors would like to acknowledge all the volunteers who participated in the study; the patient who permitted us to use their photographs, and my juniors and my colleagues who helped me throughout the study period.

\section{Disclosure}

The authors report no conflicts of interest in this work. 


\section{References}

1. Pantha R, Sharma B. Population size, growth and distribution. In: Population Monograph of Nepal. Vol 1. Kathmandu: Central Bureau of Statistics; 2003:37-86. Available from: http://cbs.gov.np/new/wpcontent/uploads/2012/Population/Monograph/Chapter\%2002\%20\%20 Population\%20Size\%20Growth\%20and\%20Distribution.pdf. Accessed July 6, 2015.

2. Hoffman W, Bomberg TJ, Hatch RA. Interalar width as a guide in denture tooth selection. J Prosthet Dent. 1986;55(2):219-221.

3. Varjão FM, Nogueira SS. Intercommissural width in 4 racial groups as a guide for the selection of maxillary anterior teeth in complete dentures. Int J Prosthodont. 2005;18(6):513-515.

4. Sellen PN, Jagger DC, Harrison A. Methods used to select artificial anterior teeth for the edentulous patient: a historical overview. Int $J$ Prosthodont. 1999;12(1):51-58.

5. Hasanreisoglu U, Berksun S, Aras K, Arslan I. An analysis of maxillary anterior teeth: facial and dental proportions. J Prosthet Dent. 2005; 94(6):530-538.

6. Shillingberg HT Jr. Esthetic considerations. In: Shillingberg HT Jr, Hobo S, Whitsett LD, Jacobi R, Brackett SE. Fundamentals of Fixed Prosthodontics, 3rd ed. Carol Stream: Quintessence Publishing Co. 1997:419-432.

7. Al Wazzan KA. The relationship between intercanthal dimension and the widths of maxillary anterior teeth. J Prosthet Dent. 2001; 86(6):608-612.

8. Kern BE. Anthropometric parameters of tooth selection. J Prosthet Dent. 1967;17(5):431-437.

9. Abdullah MA. Inner canthal distance and geometric progression as a predictor of maxillary central incisor width. $J$ Prosthet Dent. 2002;88(1):16-20.

10. McArthur DR. Determining approximate size of maxillary anterior artificial teeth when mandibular anterior teeth are present. Part I: Size relationship. J Prosthet Dent. 1985;53(2):216-218.

11. Winkler S. Essentials of Complete Denture Prosthodontics, 3rd ed. PSG Publishing Co., Littleton, Mass; 2012.
12. Al Ali KA. Current concepts of selecting teeth for complete dentures among dentists in Riyadh; Saudi Arabia. Pakistan Oral and Dental Journal. 2009;29(1):177-180.

13. Albino JE, Tedesco LA, Conny DJ. Patient perceptions of dental-facial esthetics: shared concerns in orthodontics and prosthodontics. J Prosthet Dent. 1984;52(1):9-13.

14. Ellakwa A, McNamara K, Sandhu J, et al. Quantifying the selection of maxillary anterior teeth using intraoral and extraoral anatomical landmarks. J Contemp Dent Pract. 2013;12(6):414-421.

15. Patel JR, Sethuraman R, Naveen YG, Shah MH. A comparative evaluation of the relationship of inner-canthal distance and inter-alar width to the inter-canine width amongst the Gujarati population. Journal of Advanced Oral Research. 2011;2(3):1-80.

16. Wazzan KA, Haidan A, Madi E, Mufarj AA. The relationship between facial references and mesiodistal width of maxillary anterior teeth among Saudi patients. Alexandria Dental Journal. 1995;20(4):39-45.

17. Scandrett FR, Kerber PE, Umrigar ZR. A clinical evaluation of techniques to determine the combined width of the maxillary anterior teeth and the maxillary central incisor. J Prosthet Dent. 1982;48(1):15-22.

18. Sinavarat P, Anunmana C, Hossain S. The relationship of maxillary canines to the facial anatomical landmarks in a group of Thai people. J Adv Prosthodont. 2013;5(4):369-373.

19. Hussain MW, Qamar K, Naeem S. Significance of intercommissural width and anterior teeth. Pakistan Oral and Dental Journal. 2013;33(2): 393-396.

20. Gomes VL, Gonçalves LC, do Prado CJ, Junior IL, de Lima Lucas B. Correlation between facial measurements and the mesiodistal width of the maxillary anterior teeth. J Esthet Restor Dent. 2006;18(4):196-205; discussion 205.

21. Lucas BL, Bernardino-Júnior R, Gonçalves LC, Gomes VL. Distance between the medialis angles of the eyes as an anatomical parameter for tooth selection. J Oral Rehabil. 2009;36(11):840-847.
Clinical, Cosmetic and Investigational Dentistry

\section{Publish your work in this journal}

Clinical, Cosmetic and Investigational Dentistry is an international, peer-reviewed, open access, online journal focusing on the latest clinical and experimental research in dentistry with specific emphasis on cosmetic interventions. Innovative developments in dental materials, techniques and devices that improve outcomes and patient satisfac-

\section{Dovepress}

tion and preference will be highlighted. The manuscript management system is completely online and includes a very quick and fair peerreview system, which is all easy to use. Visit http://www.dovepress. com/testimonials.php to read real quotes from published authors. 